\title{
Correction: Elaborating Models of eHealth Governance: Qualitative Systematic Review
}

Anne Granstrom Ekeland", PhD; Line Helen Linstad", MSc

Norwegian Centre for E-health Research, Troms $\varnothing$, Norway

*all authors contributed equally

\section{Corresponding Author:}

Anne Granstrom Ekeland, PhD

Norwegian Centre for E-health Research

P.o. box 35, University Hospital

Tromsø, 9038

Norway

Phone: 4795266791

Email: anne.granstrom.ekeland@ehealthresearch.no

\section{Related Article:}

Correction of: https://www.jmir.org/2020/10/e17214/

(J Med Internet Res 2020;22(11):e25853) doi: 10.2196/25853

In "Elaborating Models of eHealth Governance: Qualitative Systematic Review" (J Med Internet Res 2020;22(10):e17214), the authors noted one error.

In the Methods section of the Abstract, the following sentence specified an incorrect date range:

We searched the PubMed database using predefined search terms and selected papers published in 2010.

This sentence has been corrected to:
We searched the PubMed database using predefined search terms and selected papers published from 2010 onwards.

The correction will appear in the online version of the paper on the JMIR Publications website on November 24, 2020, together with the publication of this correction notice. Because this was made after submission to PubMed, PubMed Central, and other full-text repositories, the corrected article has also been resubmitted to those repositories.

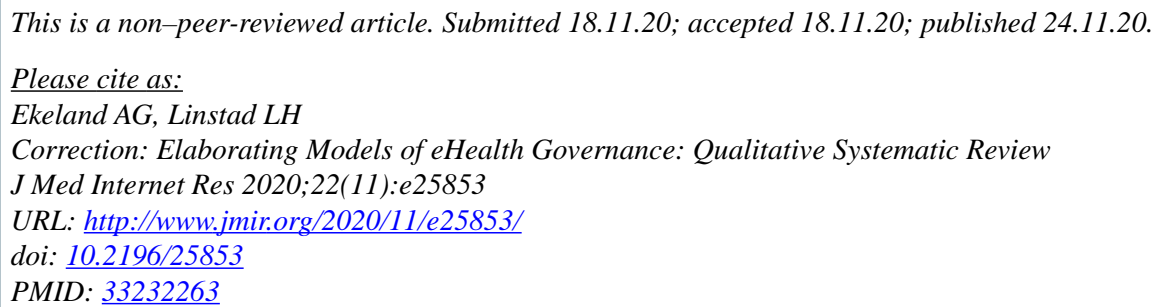

(C)Anne Granstrom Ekeland, Line Helen Linstad. Originally published in the Journal of Medical Internet Research (http://www.jmir.org), 24.11.2020. This is an open-access article distributed under the terms of the Creative Commons Attribution License (https://creativecommons.org/licenses/by/4.0/), which permits unrestricted use, distribution, and reproduction in any medium, provided the original work, first published in the Journal of Medical Internet Research, is properly cited. The complete bibliographic information, a link to the original publication on http://www.jmir.org/, as well as this copyright and license information must be included. 